ISSN: $1130-2887$

\title{
SISTEMA ELECTORAL Y CAMBIO ORGANIZATIVO EN LOS PARTIDOS POLÍTICOS: EL CASO DE COSTA RICA (1950-1998)
}

Electoral system and organizative change in the political parties:

the case of Costa Rica (1950-1998)

\author{
Sergio Alfaro Salas \\ Costarricense. Licenciado en Derecho y candidato a Doctor por la Universidad de Salamanca en el Área de Ciencia \\ Política y de la Administración. sialfaro@gugu.usal.es.
}

BIBLID [1130-2887 (2001) 27, 67-87]

Fecha de recepción: diciembre de 2000

Fecha de aceptación y versión final: marzo de 2001

RESUMEN: El objetivo principal del presente artículo es evaluar el grado real de influencia del derecho electoral como variable independiente del cambio organizativo en los partidos políticos, a la vez que realiza un examen preliminar de las dimensiones de afectación de la misma en el caso costarricense. En él se propone y se prueba un sistema de identificación de la relación existente entre las citadas variables, buscando la influencia de los cambios relevantes en el derecho electoral, previamente detectados, sobre tres dimensiones de afectación dentro de la organización partidista: el perfeccionamiento de su aparato burocrático, el balance de poder interno y el control estatal.

Palabras clave: Organización de partidos, cambio organizativo, sistema electoral, derecho electoral, Costa Rica.

ABSTRACT: The main scope of this article is valuate, in the costarrican case, the real degree of influence of the electoral rules change as independent variable for the parties organizational change, secondly, it makes a previous examination of the dimensions that this factor can affect. It creates and tries an identification system of the relationship among this variables and also searchs the influence of the detected relevant legislation changes into three major dimensions of party organization: perfectioning of the party «aparatus», internal balance of power and state control.

Key words: Party organization, organizative change, electoral system, electoral law, Costa Rica. 
SERGIO ALFARO SALAS

SISTEMA ELECTORAL Y CAMBIO ORGANIZATIVO EN LOS PARTIDOS POLÍTICOS:
EL CASO DE COSTA RICA (1950-1998)

\section{INTRODUCCIÓN}

Este trabajo centra su atención en los efectos de la variación del derecho electoral sobre los partidos políticos costarricenses, sobre todo, en lo que a sus cambios organizativos se refiere. Los partidos, como organizaciones humanas que son, sufren un proceso constante de evolución basado en cambios dentro de su estructura organizativa, los cuales son provocados por una serie de factores «medioambientales» e internos que determinan la dirección de dichos cambios. Del éxito de la organización en este proceso de adaptación dependerá su continuidad o su muerte'.

A partir de esta idea general, Richard, Katz y Peter Mair (1990) plantean una investigación que pretende estudiar la génesis del cambio organizativo en los partidos europeos, partiendo de los factores explicativos del cambio partidista recogidos en la literatura especializada, entre los cuales se encuentra el sistema electoral ${ }^{2}$.

Por sistema electoral se entiende, según Vallès y Bosch (1997: 33), «el conjunto de elementos normativos y sociopolíticos que configura el proceso de designación de titulares de poder, cuando este proceso se basa en preferencias expresadas por los ciudadanos de una determinada comunidad política». Asimismo, dicho concepto tiene dos posibles interpretaciones o vertientes de análisis, complementarias y compatibles entre sí, que son la perspectiva jurídica y la perspectiva politológica. La primera de éstas trata de cubrir el estudio de las «reglas de juego» de la comunidad política y su denominación específica es «derecho electoral» ${ }^{3}$. La segunda perspectiva envolverá las variables sociológicas y del entorno en que se mueven esos modelos jurídicos.

Si se toma como premisa que ese cambio organizacional es complejo y multifactorial, como defienden Katz y Mair (1990 y 1994), no se puede esperar que el derecho electoral funcione como variable independiente de la totalidad de cambios, e incluso debería causar sorpresa si explica totalmente algún cambio. También es de conocimiento general que la variable en estudio, finalmente, es controlada por los propios partidos a través de las instituciones legislativas que establece la democracia representativa, razón por la cual puede funcionar también como variable dependiente tanto de procesos intra-partidistas como de fuerzas ajenas a los partidos políticos ${ }^{4}$.

1. Sobre la teoría de la contingencia en las organizaciones partidistas ver PANEBIANCO (1982: caps. X y XI).

2. Esta investigación tiene como resultado el libro How Parties Organize (1994).

3. Según CRESPO (1997: 229), el concepto derecho electoral comprende «todo el conjunto de disposiciones legales que regulan los diversos aspectos del procedimiento o proceso electoral...».

4. VALLÉS y BOSCH (1997: 118) reconocen tres campos esenciales de afectación del sistema electoral como variable independiente: el impacto sobre la representación parlamentaria, la influencia sobre los partidos políticos en su ámbito organizacional y en sus estrategias electorales y, por último, sobre los electores y sus estrategias de decisión. Como variable dependiente, el sistema electoral dependerá fundamentalmente de factores sociopolíticos, entre los que están los partidos políticos como agentes del sistema político. Estos últimos, según PANEBIANCO (1982: 43) pueden tender a dominar el ambiente en que se desenvuelven y no sólo se adaptan a él pasivamente. Con base en la anterior afirmación, el derecho electoral, al formar parte de dicho ambiente, puede ser uno de los objetos de 
El presente análisis pretende aislar el derecho electoral como variable independiente que explica los cambios partidistas, con el objetivo de determinar cómo y en qué medida su variación ha afectado las estructuras formales de los partidos políticos de Costa Rica durante la segunda mitad del siglo Xx. Esta estrategia de abordaje permitirá dar a esta variable su peso específico correcto, condición indispensable para proceder a un posterior estudio multifactorial. Este objetivo implica generar una metodología que permita incluir en el análisis sólo aquellos cambios del derecho electoral que funcionen como variable explicativa de los cambios en los partidos políticos y que, a la vez, excluya a los que no cumplan dicha función.

Conseguida la identificación de los cambios relevantes del derecho electoral que han afectado directamente la estructura formal de cada uno de los partidos políticos, se procederá a estudiar el contenido de los mismos, comparándolos directamente con la normativa interna afectada. Esto permitirá determinar si el cambio organizativo se limitó únicamente a un ajuste legal, o bien, tuvo un alcance mayor al exigido por la ley.

Asimismo, en caso de existir una afectación, se estudiarán las variaciones en la organización en tres diferentes dimensiones no excluyentes entre sí, a saber: el perfeccionamiento o profesionalización de las burocracias partidistas, las relaciones de poder que éstos exhiben en sus normativas internas y el control del Estado sobre la organización. Lo anterior pretende la identificación de las repercusiones inmediatas de dichos cambios legislativos que sirvan de orientación para estudios posteriores y más ambiciosos.

\section{Las unidades de observación}

El trabajo se centra en cuatro partidos políticos, tres de ellos de carácter nacional y uno de carácter provincial. Dentro del primer nivel, Liberación Nacional (PLN), la Unidad Social Cristiana (PUSC) y Fuerza Democrática (FD); en el segundo, Unión Agrícola Cartaginés (PUAC). El criterio de selección de casos es, en los de ámbito nacional, que dichas organizaciones son las más importantes en la composición de la Asamblea Legislativa 1998-2002; el caso del PUAC resulta relevante por ser el único partido provincial con resultados electorales estables y relativamente exitosos en el período que va desde 1970 hasta 1998.

\section{II. ¿POR QUÉ EL DERECHO ELECTORAL?}

La pregunta que guía este trabajo es ¿cómo y en qué medida afecta el cambio del derecho electoral a las organizaciones partidistas en su carácter organizativo formal? Responder que esta variable provoca cambios en los partidos políticos es una verdad

control de dichas organizaciones de carácter agresivo y, por lo tanto, puede estar dentro de las «estrategias de dominio» de los propias organizaciones partidistas. 
de Perogrullo, razón por la cual se debe ir más allá y buscar el nivel real de incidencia de la variable y los cambios cualitativos de la organización provocados por ella.

La función principal del derecho electoral consiste en regular el espectro de la actividad política de un país, dentro de la cual se encuentran sus actores más preponderantes: los partidos políticos. Estas organizaciones se enmarcan dentro de la lógica de la libertad de asociación, que implica la libertad de los asociados para fijar su forma particular de funcionamiento interno, pero, al tener fines públicos, se enfrentan a un control estatal que pretende limitar la natural tendencia oligárquica de los partidos (Michels, 1996), la cual se opone al ideal democrático de igualdad de oportunidades de participación. Así, la intervención del Estado provoca una reacción del derecho electoral tendiente a regular el ejercicio del poder en el interior de la organización, razón suficiente para que se justifique plenamente el giro de investigación que este trabajo pretende.

Este intento regulador, según Santaolalla López,

«no debe pretender ni forzar una vida democrática químicamente pura en el interior de los partidos y grupos parlamentarios, ni caer en la tentación opuesta de sacrificar toda consideración al predominio de los dirigentes... Por eso - por la dificultad de tratamiento jurídico- creo que tenemos que resignarnos a que la democracia interna de los partidos sea una democracia deficiente» (1992: 103). Las cursivas no son del original.

Esta afirmación refuerza el argumento de que la intromisión del mundo jurídico en los partidos no es inocua; todo lo contrario, las determinaciones que se impongan jurídicamente a los actores políticos van a marcar sus formas de actuación y, por ende, la vida y estilo de acción de sus organizaciones. El derecho electoral, al regularlas, buscará la mayor seguridad posible en cuanto a eficacia de la normativa y para conseguirlo marcará obligaciones y límites que deben integrarse obligatoriamente a las normas internas o estatutos de cada organización. Así, la influencia del derecho electoral en el partido político puede repercutir tanto en los equilibrios internos de poder como en la configuración del sistema de partidos, pero su influencia será mucho mayor cuando algunas de las estructuras internas de la organización sean impuestas por aquél (Katz y Mair, 1990: 21) como es el caso de Costa Rica.

\section{LAS FUENTES DE DATOS}

Según el derecho electoral costarricense, todos los cambios de estructura formal que se produzcan en los partidos y en sus estatutos deben inscribirse en los archivos del Registro de Partidos del Registro Civil y, por ende, ajustarse completamente a la normativa vigente, siendo dicho registro el encargado de velar por el cumplimiento de tal obligación desde el nacimiento de un partido hasta su pérdida de vigencia legal. Además, la Procuraduría General de la República, a través del Sistema Nacional de Legislación Vigente (SINALEVI) mantiene una base de datos de legislación, en la cual se pueden obtener las normas jurídicas originales y todas aquellas que significaron un cambio en éstas, 
de manera tal que se puede dar un correcto seguimiento a la evolución de la legislación en el período estudiado.

Así, las fuentes primarias de datos utilizadas en la presente investigación y en las cuales se observará la naturaleza y contenidos de los cambios organizativos provocados por la variable en estudio, provienen de dichas instituciones.

Además, siendo la base fundamental de regulación interna de los partidos políticos su estatuto, dicho documento y su evolución resultan imprescindibles en este estudio. A pesar de ello, el estatuto es sólo una muestra de la organización formal del partido y no existe garantía de que ésta refleje el real funcionamiento del mismo, ante lo que resultaría válido el siguiente cuestionamiento: ¿por qué utilizar los estatutos de los partidos como fuente de información para observar su cambio organizativo?

La respuesta la dan Katz y Mair (1990: 17), este tipo de normas internas constituyen la cara pública y formal de la organización, en ellas se plasman las «reglas» que marcan la vida y la legalidad del partido, por.ello, el estudio de sus cambios en forma diacrónica puede evidenciar las manifestaciones más claras de sus cambios organizacionales. Es muy claro que no todos los cambios acaecidos constarán en esa «historia oficial» del partido, de manera que resulta necesario buscar la explicación de éstos mediante un análisis multivariable que acuda a otras fuentes de información más allá de las oficiales, las cuales permitan tener una visión completa de la realidad.

A pesar de esta inexactitud o parcial reflejo de la realidad, las normas internas de los partidos siguen siendo importantes, ellas sostienen la vida del partido e impiden su desintegración, lo que en sí mismas les concede un valor como fuente primaria de datos duros para la investigación. En este sentido los estatutos tienen, según Katz y Mair (1990: 16), cuatro características esenciales:

a. «Reflejan los cambiantes equilibrios de poder existentes dentro del partido» a la vez que muestran las variaciones que se producen históricamente en ese equilibrio 5 .

b. Son una arma más, utilizable en las luchas internas por el poder.

c. Son la cara pública del partido, lo que es esencial en los sistemas con una fuerte regulación jurídica en materia de organizaciones partidistas.

d. Sirven como contrapunto para comparar las relaciones internas de poder que se producen en la realidad de estas organizaciones.

Es evidente, a partir de lo argumentado, la necesidad de medir la cantidad y alcance de la influencia del derecho electoral en el cambio organizativo formal de los partidos, de forma tal que se le conceda al derecho electoral el peso específico y la importancia que en realidad merece como variable independiente. Este ejercicio elimina la posibilidad de sobredimensionamiento o de indiferencia del investigador ante esta variable, sobre todo, al abordar el estudio general del cambio organizativo en los partidos políticos.

5. El original en inglés dice que las normas «map the changing balance of intra-organizational power». 
A pesar de reconocer la característica multifactorial del cambio organizativo en los partidos políticos y la imperfección del constreñimiento legal a la espontaneidad de las mismas, se utilizará una hipótesis de trabajo que ignore las condiciones señaladas, con el fin de encontrar la proporción explicativa correcta de la variable utilizada. La hipótesis de trabajo será la siguiente: «El cambio en la configuración del derecho electoral provoca directamente cambios en las organizaciones partidistas».

\section{CATEgoríAS y DimEnSIONES PROPUESTAS}

El método propuesto para verificar la influencia de los cambios del derecho electoral en los cambios de las estructuras partidistas tomará en cuenta tanto el ámbito temporal como el ámbito de los contenidos. De acuerdo con la hipótesis planteada, un cambio legislativo que promueva un cambio obligatorio en la estructura del partido debe darse en una relación temporal corta, en el sentido de que el partido debe adaptarse rápidamente porque, de lo contrario, su estructura, su funcionamiento y sus actos podrían devenir ilegales. Otra posibilidad es que un partido realice un cambio antes de que se apruebe una legislación de carácter «aperturista» y así «ganar la partida» a sus competidores y con ello legitimarse frente a los votantes.

De la misma forma, los cambios en los contenidos de la normativa interna deben ser iguales, en cuanto a temática, a los cambios del derecho electoral. Esto debido a que una reforma estatutaria provocada por el cambio normativo puede estar acompañada de cambios estructurales y de funcionamiento interno que no tienen que ver directamente con la reforma legal, por lo que, de no tener en cuenta los contenidos de ambas reformas, podríamos caer en confusiones a la hora de evaluar la incidencia de la variable en el cambio organizativo.

Para efectos prácticos se establecerán categorías para los cambios que se producen en la organización formal, de forma tal que aseguren un método para obtener resultados evaluables. Se utilizará para el análisis una clasificación de los cambios internos de los partidos en tres categorías ${ }^{7}$ que se exponen en el Cuadro I.

Esta forma de organizar los cambios observados permite clasificarlos, lo que, a su vez, permitirá discriminar los que no tienen relación con la variable en estudio de aquellos en los que la explicación del cambio puede ser multifactorial, al tiempo que es posible identificar los cambios explicados totalmente por el «derecho electoral». En otras palabras, el sistema propuesto funciona como un filtro que permite distinguir los cambios relacionados directamente con la variable en estudio -categoría 2- así

6. Este supuesto es posible en el caso de que un partido tenga certeza de que una eventual reforma será aprobada. Esta actitud puede empatarse con las «estrategias de dominio» que describe PANEBIANCO (1982: 45).

7. Para efectos del análisis se asignará a cada una de estas categorías un valor único que la identifique, con el fin de agrupar alrededor del mismo los cambios que correspondan a cada una de ellas y así determinar cuantitativamente lo observado. 
Cuadro I. Categorización de los cambios organizativos

\begin{tabular}{c|l}
\hline Valor & \multicolumn{1}{c}{ Categoría } \\
\hline 0 & $\begin{array}{l}\text { Aquellos cambios que no tienen que ver en absoluto con la variable estudiada (para el análisis multivariable el } \\
\text { derecho electoral estaría descartado como variable explicativa del cambio). }\end{array}$ \\
\hline 1 & $\begin{array}{l}\text { Los cambios que, tanto en tiempo como en parte de su contenido, se ajustan a la variable (para el análisis } \\
\text { multivariable el derecho electoral debe ser tomado en cuenta como una de las variables explicativas). }\end{array}$ \\
\hline 2 & $\begin{array}{l}\text { Los cambios que se ajusten en su totalidad, en tiempo y en contenido, a la variable (en este caso no es posible hacer } \\
\text { un análisis multivariable ya que el derecho electoral explica el cambio de forma completa). }\end{array}$ \\
\hline
\end{tabular}

como aquellos que se pueden explicar parcialmente a raíz de un cambio en el derecho electoral -categoría $1-$.

Una vez realizado este proceso se analizarán los cambios internos identificados dentro de la categoría 2, tomando en cuenta tres dimensiones de la organización que se ven afectadas por el cambio en la normativa:

- Cambios operativos o de perfeccionamiento en el funcionamiento institucional.

- Cambios en el equilibrio de fuerzas internas.

- Cambios en favor del control estatal.

La utilidad de estas dimensiones descansa en la posibilidad de hacer un estudio posterior y más detallado, en el que se pueda analizar tanto la profesionalización del aparato burocrático del partido como los procesos de apertura o protección de las elites y sus efectos sobre la organización en general y, por último, se podrá analizar la incidencia del Estado en la vigilancia de la organización ${ }^{8}$.

También, las dimensiones de afectación pueden ser usadas para estudiar los efectos de los cambios discriminados del presente trabajo (categorías 0 y 1 ). Esto facilitaría, en un análisis multivariable de la totalidad de cambios, la delimitación de áreas comunes de incidencia de los mismos, tanto en el nivel formal como en el informal, e independientemente de si éstos son explicados por el derecho electoral o por otras variables.

\section{Clasificación de los CAmbios}

Procede ahora, como se explicó, separar aquellos cambios que son explicados directamente por la variable en estudio de aquellos que lo son parcialmente y, por supuesto, desechar los que no tienen relación alguna con ella. Con este fin se muestran los cambios legislativos observados en el período, su fecha de aprobación y contenidos esenciales; dichas variaciones serán luego comparadas con los cambios observados en

8. Para PANEBIANCo (1982: 315 a 334) de la estabilidad de la coalición dominante y de la forma del «mapa de poder» del partido (organigrama) depende el proceso de institucionalización del partido. Esto es importante ya que se parte de la relación que establece HunTINGTON (1968/1997: cap. VII) de que la estabilidad política en las sociedades modernas depende del equilibrio que han conseguido en la relación institucionalización-participación. 
SERGIO ALFARO SALAS SISTEMA ELECTORAL Y CAMBIO ORGANIZATIVO EN LOS PARTIDOS POLÍTICOS: EL CASO DE COSTA RICA (1950-1998)

Cuadro II. Los cambios sobre organización de partidos políticos en el derecho electoral 1949-1999

\begin{tabular}{|c|c|c|c|}
\hline FECHA & $\begin{array}{c}\text { NÚMEROIDL } \\
\text { LEY }\end{array}$ & $\begin{array}{c}\text { LEY } \\
\text { AFECTADA }\end{array}$ & CONTENIDOS PERTINENTES DEL CAMBIO LEGISLATIVO \\
\hline $18-07-1956$ & 2036 & C.P. & - Crea la financiación estatal de los partidos políticos. \\
\hline $06-06-1958$ & 2214 & C.P. & - Se concede remuneración a los regidores municipales. \\
\hline $20-05 \cdot 1959$ & 2345 & C.P. & $\begin{array}{l}\text { - Introduce la obligatoriedad del voto. } \\
\text { - Introduce la obligatoria inscripción y cedulación. }\end{array}$ \\
\hline $12-05 \cdot 1961$ & 2741 & C.P. & $\begin{array}{l}\text { - Fija el número de diputados en } 57 \\
\text { Fija en el } 1 \text { de mayo la instalación de los municipios. }\end{array}$ \\
\hline $31-05 \cdot 1965$ & 3508 & C.E. & $\begin{array}{l}\text { - Tamaño de las circunscripciones. } \\
\text {. Forma de llenar vacantes en la Asamblea Legislativa. }\end{array}$ \\
\hline $25-10-1965$ & 3555 & C.E. & - Cambia requisitos para ser electo regidor o síndico municipal. \\
\hline $25-10-1965$ & 3556 & C.E. & - Establece el nombramiento de fiscales regionales de los partidos políticos ante el Registro Civil. \\
\hline 03-06-1969 & 4341 & C.E. & $\begin{array}{l}\text { - Cambia los requisitos de afiliación para inscribir partidos. } \\
\text { - Regula la propaganda electoral. } \\
\text { - Cambia la regulación sobre financiamiento de partidos políticos. }\end{array}$ \\
\hline $11-07.1969$ & 4349 & C.P. & - Introduce la imposibilidad absoluta de reelección presidencial. \\
\hline $27-07 \cdot 1971$ & 4813 & C.E. & $\begin{array}{l}\text { - Introduce la obligación de renovar la inscripción de los partidos que no obtuvieren al menos una } \\
\text { cantidad de votos igual a la necesaria para su inscripción. }\end{array}$ \\
\hline $07-10 \cdot 1971$ & 4859 & C.E. & - Reduce la edad mínima legal para emitir el voto de 20 a 18 años. \\
\hline $16-05 \cdot 1972$ & 4973 & C.P. & $\begin{array}{l}\text { - Reduce el porcentaje de votos necesario para acceder al financiamiento estatal por los partidos } \\
\text { políticos. }\end{array}$ \\
\hline $04-06 \cdot 1975$ & 5698 & C.P. & - Levantamiento de la prohibición al Partido Comunista. \\
\hline $20-07-1977$ & 6068 & C.E. & - Incluye limitaciones temporales al Ejecutivo para variar la división territorial administrativa. \\
\hline 03-09-1981 & 6629 & C.E. & - Introduce, como responsabilidad de los partidos, la idoneidad y capacidad de sus candidatos. \\
\hline $23 \cdot 12 \cdot 1982$ & 6833 & C.E. & $\begin{array}{l}\text { - Regula la fusión de partidos políticos. } \\
\text { - Se cambia la regulación sobre funcionarios con prohibición de participación política. } \\
\text { - Reduce el porcentaje de votos necesarios para obtener financiamiento estatal de partidos políticos. }\end{array}$ \\
\hline $27-05 \cdot 1988$ & 7094 & C.E. & $\begin{array}{l}\text { - Aumenta los requisitos de inscripción de partidos políticos. } \\
\text { - Cambia los requisitos mínimos de contenido de los estatutos de partidos políticos. } \\
\text { - Regula la distribución del financiamiento estatal en las coaliciones de partidos. } \\
\text { - Cambia el sistema de adhesión para la inscripción de partidos. } \\
\text { - Cambia la regulación sobre designación de candidatos y limita temporalmente la realización de } \\
\text { primarias. } \\
\text { - Regula la propaganda política y crea la «tregua navideña». } \\
\text { - Cambia las reglas del financiamiento estatal de partido políticos. }\end{array}$ \\
\hline 08.03.1990 & 7142 & $\begin{array}{l}\text { Ley de } \\
\text { igualdad } \\
\text { social de la } \\
\text { mujer }\end{array}$ & $\begin{array}{l}\text { Establece que los partidos deben incorporar mecanismos eficaces para mejorar la participación } \\
\text { femenina en los partidos políticos y dedicar un porcentaje de su presupuesto para su formación y } \\
\text { participación. }\end{array}$ \\
\hline 10-12-1996 & 7653 & C.E. & $\begin{array}{l}\text { - Reforma las reglas de establecimiento de la división territorial administrativa. } \\
\text { - Aumenta los contenidos mínimos de los estatutos. } \\
\text { - Cambia la organización legal y jerarquiza las asambleas internas de los partidos, esencialmente impone } \\
\text { medidas de acción afirmativa a favor de la mujer. } \\
\text { - Introduce, como causal de cancelación de la inscripción, la no participación en las elecciones. } \\
\text { - Cambia la regulación sobre la designación de candidatos. } \\
\text { - Regula la propaganda política, la realización de mítines, y la forma de reunión de los partidos. } \\
\text { - Cambia los criterios de prohibición de participación de funcionarios en actividades político } \\
\text { electorales. } \\
\text { - Cambia el sistema de fiscales del partido ante el Registro Civil. } \\
\text { - Varía todo el sistema de financiamiento y control del financiamiento de los partidos. } \\
\text { - Permite la doble postulación de un candidato en tanto sea a presidente y diputado a la vez. } \\
\text { - Regula el transporte durante el día de las elecciones. } \\
\text { - Establece la obligación de inscripción y demostración de idoneidad a las empresas encuestadoras y } \\
\text { prohíbe la divulgación de encuestas desde dos dias antes de la elección y el mismo dia inclusive. }\end{array}$ \\
\hline $02-07 \cdot 1997$ & 7675 & C.P. & $\begin{array}{l}\text { - Agrega, a modo de principio general, las condiciones y garantías de pluralismo, no discriminación por } \\
\text { género, y democracia interna de los partidos políticos. } \\
\text { - Varía las reglas del financiamiento estatal a los partidos, cambia al criterio del } 0,19 \% \text { del PIB del ano } \\
\text { trasanterior, el umbral lo baja al } 4 \% \text { o la elección de un diputado para partidos provinciales. }\end{array}$ \\
\hline
\end{tabular}

C.P. $=$ Constitución Política; C.E. $=$ Código Electoral.

Fuente: Elaboración propia a partir de la base de datos del SINALLVI. 
cada uno de los partidos estudiados, los que se expondrán incluyendo también su fecha, contenido y su clasificación de acuerdo con las categorías mencionadas.

\section{a. Los cambios en el derecho electoral}

En el Cuadro II se observa la evolución de las normas relativas a la organización de los partidos políticos, tanto a nivel constitucional como a nivel de ley común. Aunque el derecho electoral ha sufrido otros cambios durante el período de estudio no es menester de esta investigación incorporarlos, ya que los mismos se refièren básicamente a procedimientos referentes a la organización de las elecciones generales -horarios de constitución de las juntas electorales, formas de imprimir, trasladar y hacer llegar las papeletas a los recintos, formas del escrutinio y otros-, detalles que si bien influyen en la organización del partido para el día de las elecciones, no influyen en el objeto de estudio que es su estructura permanente.

\section{b. Los cambios en los partidos, exclusión de casos}

Ahora se procederá a clasificar los cambios observados en cada partido de manera tal que aquellos que sean clasificados en las categorías 0 y 1 quedarán excluidos del análisis. Es necesario recordar que dicho estudio se hace a cada partido por separado ya que son unidades de observación independientes.

\section{El Partido Unión Agrícola Cartaginés:}

De acuerdo con la clasificación, en el caso del PUAC, sólo es posible identificar un cambio interno de la organización, aunque un poco tardío, que se relaciona directamente con el cambio en el derecho electoral. El mismo se observa en la Asamblea Provincial del 18 de agosto de 1993 y consiste en un ajuste del estatuto provocado por la Ley 7142 de 1990 .

Cuadro III. Los cambios estatutarios del PUAC

\begin{tabular}{c|c|l}
\hline $\begin{array}{c}\text { Fecha del cambio } \\
\text { estatutario }\end{array}$ & Categoría & \multicolumn{1}{c}{ Implicaciones del cambio } \\
\hline $23-06-1969$ & 0 & - Constitución del partido ante notario público. \\
\hline $13-07-1969$ & 0 & - Aprobación de estatutos. \\
& 0 & - Nombramiento del Comité Ejecutivo. \\
\hline $14-05-1988$ & 0 & - Ratificación del presidente y elección del resto del Comité Ejecutivo. \\
\hline & 0 & - Nombramiento de un secretario ejecutivo provincial. \\
$18-08-1993$ & 2 & $\begin{array}{l}\text { - Ratificación del Comité Ejecutivo. } \\
\text { y Ajuste de estatutos al artículo 58 del Código Electoral, contenidos mínimos de los estatutos, } \\
\text { y a los artículos 5 y 6 de la Ley de Igualdad Social de la Mujer, no discriminación por razones } \\
\text { de sexo. }\end{array}$ \\
\hline
\end{tabular}


SERGIO ALFARO SALAS

El Partido Fuerza Democrática:

Cuadro IV. Los cambios estatutarios en FD

\begin{tabular}{c|c|l}
\hline $\begin{array}{c}\text { Fecha del cambio } \\
\text { estatutario }\end{array}$ & Categoría & \multicolumn{1}{c}{ Implicaciones del cambio } \\
\hline $21-11-1992$ & 0 & - Constitución ante notario público. \\
\hline & 0 & $\begin{array}{l}\text { - Nombramiento del Comité Ejecutivo Nacional. } \\
\text { - Modificación de estatutos: }\end{array}$ \\
& 2 & $\begin{array}{l}\text { - Ajuste de acuerdo a la Ley de Igualdad Social de la Mujer. } \\
\text { 03-07-1993 }\end{array}$ \\
& 0 & - Variación del sistema de elección de candidatos a regidores y síndicos municipales. \\
& 0 & - Variación del sistema de elección de candidatos a presidente y vicepresidentes. \\
\hline $30-11-1996$ & 0 & - Nombramiento del Comité Ejecutivo Nacional. \\
& 0 & - Combramiento del Comité Político. \\
\hline 30-09-1997 & 2 & - Reforma general de estatutos, ajuste a la Ley 7653 del 10-12-1996. \\
\hline Fuente: Elaboración propia a partir de los archivos del Registro de Partidos del Registro Civil.
\end{tabular}

En el caso de FD es posible observar dos cambios organizativos directamente relacionados con los cambios en el derecho electoral, éstos son los sucedidos en las Asambleas Nacionales del 3 de julio de 1993 y del 30 de agosto de 1997, provocados por las Leyes 7142 de 1990, 7653 de 1996 y 7675 de 1997.

\section{El Partido Unidad Social Cristiana}

En cuanto al Pusc, los cambios que se produjeron únicamente basándose en la variable de estudio son los que se observan en las Asambleas General y Nacional de 21 de noviembre de 1983 y de 29 de junio de 1997, a causa de las Leyes 6833 de 1982, 7653 de 1996 y 7675 de 1997. Además de éstos, hay otros cuatro cuya explicación no parece deberse únicamente al cambio en la normativa y en los que pudieron haber intervenido otros factores, éstos son los fechados en 30 de enero de 1988, 19 de octubre de 1991 y 16 de junio de 1996. En ellos se nota la influencia de las Leyes 7094 de 1988, 7142 de 1990 y 7653 de 1996, pero no se limitan únicamente a lo que la ley pide y van más allá, lo que los excluye de la categoría 2.

\section{El Partido Liberación Nacional}

Es en el PLN donde más cambios internos han ocurrido, lo cual es lógico si tomamos en cuenta la edad del partido (nacido en 1952), pero es curioso observar cómo los cambios provocados, total o parcialmente, por el derecho electoral se acumulan en la década de 1990. En los 38 años anteriores las variaciones que tuvieron lugar, salvo una en concreto, no pueden relacionarse directamente con cambios en la legislación. Así, los influidos directamente por el cambio en el derecho electoral (categoría 2) son los de las Asambleas Plenaria y Nacional de 29 de abril de 1956, de 22 de agosto de 1992, 
SERGIO ALFARO SALAS

SISTEMA ELECTORAL Y CAMBIO ORGANIZATIVO EN LOS PARTIDOS POLÍTICOS:

EL CASO DE COSTA RICA (1950-1998)

Cuadro v. Los cambios estatutarios en el PUSC

\begin{tabular}{|c|c|c|}
\hline $\begin{array}{l}\text { Fecha del cambio } \\
\text { estatutario }\end{array}$ & Categoría & Implicaciones del cambio \\
\hline $14-06-1977$ & 0 & - Los partidos Renovación Democrática y Republicano Calderonista forman la Coalición Unidad. \\
\hline $21-11-1983$ & 2 & $\begin{array}{l}\text { - Los partidos de Coalición Unidad y el Partido Renovación Democrática se fusionan en el Partido Unidad } \\
\text { Social Cristiana. }\end{array}$ \\
\hline 28-04-1984 & 0 & - Se inscriben los Estatutos del PUSC. \\
\hline $30-06-1984$ & 0 & - Cambia el presidente del Comité Ejecutivo Nacional \\
\hline $30-08-1987$ & 0 & - Cambia el secretario general del Comité Ejecutivo Nacional. \\
\hline $30-01-1988$ & 0 & $\begin{array}{l}\text { - Se inscribe un reglamento para la realización de la Convención Nacional (primarias presidenciales) y se fija } \\
\text { fecha el día } 27 \cdot 11 \cdot 1988 \text {. } \\
\text { - Se hace una modificación general del estatuto. }\end{array}$ \\
\hline $12-02-1989$ & 0 & - Se cambia la totalidad del Comité Ejecutivo Nacional. \\
\hline $23.04-1989$ & $\begin{array}{l}0 \\
0 \\
0\end{array}$ & $\begin{array}{l}\text { - Se designa candidato presidencial para la elección de } 1990 \text { al ganador de la Convención Rafael Ángel } \\
\text { Calderón Fournier. } \\
\text { - Reforma de estatutos: } \\
\text { - Varían las funciones y composición del Directorio Político Nacional. } \\
\text { - Se agrega un nuevo frente del partido: el cooperativista. } \\
\text { - Se agrega al Directorio Político un fiscal y un tercer vicepresidente. }\end{array}$ \\
\hline 08-04-1990 & 0 & - Cambios en el Comité Ejecutivo, el presidente, un vicepresidente, el tesorero y el secretario general. \\
\hline 19-10-1991 & $\begin{array}{l}0 \\
0 \\
1 \\
0 \\
0 \\
0 \\
0\end{array}$ & $\begin{array}{l}\text { - Reforma de la Carta Ideológica (programa máximo). } \\
\text { - Reforma general del estatuto, esencialmente en los siguientes puntos: } \\
\text { - Estructura de la Asamblea General y la Asamblea Nacional. } \\
\text { - Se crea la Secretaría de Promoción y Participación Política de la Mujer. } \\
\text { - Se crea la Organización de Profesionales Socialcristianos y modifica el Frente de Cooperativistas. } \\
\text { - Se modifica lo referente a la Juventud Socialcristiana. } \\
\text { - Se modifica el Tribunal de Ética y Disciplina, así como el Tribunal de Elecciones Internas. } \\
\text { - Se crea una Auditoría Interna y se regulan las Auditorías Externas. }\end{array}$ \\
\hline 07-06-1992 & 0 & - Cambia el Comité Ejecutivo Nacional. \\
\hline 02-05-1993 & 0 & $\begin{array}{l}\text { - Cambia el secretario general, se excusa por exceso de trabajo al ser el presidente de la Asamblea } \\
\text { Legislativa y se recomienda que se le vuelva a nombrar cuando termine su período en dicho cargo. }\end{array}$ \\
\hline $31-07-1994$ & 0 & - Regresa el secretario general al cumplir el período de la presidencia legislativa. \\
\hline 05-03-1995 & 0 & - Cambia el secretario general. \\
\hline $16-06-1996$ & $\begin{array}{l}0 \\
1 \\
0 \\
0 \\
0\end{array}$ & $\begin{array}{l}\text { - Reforma estatutaria, esencialmente en los puntos siguientes: } \\
\text { - Se agregan cuatro vicepresidentes al Comité Ejecutivo Nacional. } \\
\text { - Se incluye el } 40 \% \text { de ley de representación femenina en asambleas. } \\
\text { - Cambia la composición de la Asamblea Nacional. } \\
\text { - Cambian los plazos de nombramiento de miembros del Comité Ejecutivo Nacional. } \\
\text { - Se nombra nuevo Comité Ejecutivo Nacional. }\end{array}$ \\
\hline $02-02-1997$ & $\begin{array}{l}0 \\
0 \\
0\end{array}$ & $\begin{array}{l}\text { - Se inscribe el reglamento de elecciones primarias para regidores y síndicos municipales para la elección de } \\
1998 . \\
\text { - Se incorpora la «Carta Socialcristiana a Costa Rica» (Carta Ideológica) como principios y programa } \\
\text { ideológico. } \\
\text { - Se produce una reforma general del estatuto. }\end{array}$ \\
\hline 29-06-1997 & $\begin{array}{l}2 \\
2\end{array}$ & $\begin{array}{l}\text { - Cambia el tesorero del Comité Ejecutivo Nacional. } \\
\text { - Modificación de estatutos: } \\
\text { - Se agregan al estatuto detalles de operación de la auditoria interna. } \\
\text { - Se fija sede para recibir notificaciones del Tribunal Supremo de Elecciones. }\end{array}$ \\
\hline $20-05.1998$ & 0 & $\begin{array}{l}\text { - Cambian algunos cargos del Comité Ejecutivo, presidente, un vicepresidente y el secretario general (este } \\
\text { último aún no ha sido ratificado por la Asamblea). }\end{array}$ \\
\hline
\end{tabular}

Fuente: Elaboración propia a partir de los archivos del Registro de Partidos del Registro Civil. 
SERGIO ALFARO SALAS

SISTEMA ELECTORAL Y CAMBIO ORGANIZATIVO EN LOS PARTIDOS POLÍTICOS:

EL CASO DE COSTA RICA (1950-1998)

de 7 de diciembre de 1996 y 21 de mayo de 1997, provocados por las Normas 7142 de 1992 y 7653 de 1996 y los cambios organizativos de la categoría 1, que aparentemente tienen otros factores explicativos además del estudiado, son: el de 10 de agosto de 1991, el de 19 de setiembre de 1992 y algunos del 21 de mayo de 1997, influidos por las Leyes 7094 de 1988, 7142 de 1992 y 7653 de 1996.

\section{EL CONTENIDO DE LOS CAMBIOS ORGANIZATIVOS Y LAS DIMENSIONES DE AFECTACIÓN}

Una vez determinados los cambios que se explican directamente por el cambio en el derecho electoral, se estudiarán los mismos con más detalle ya que, como se dijo, es

Cuadro VI a. Los cambios estatutarios en el PLN, 1952-1989

\begin{tabular}{|c|c|c|}
\hline $\begin{array}{c}\text { Fecha del cambio } \\
\text { estatutario }\end{array}$ & Categoría & Implicaciones del cambio \\
\hline 15-04-1952 & 0 & - Constitución ante notario público. \\
\hline $29-04-1956$ & $\begin{array}{l}0 \\
2\end{array}$ & $\begin{array}{l}\text { - Cambio de Comité Ejecutivo Nacional. } \\
\text { - Reinscripción del partido ordenada por ley. }\end{array}$ \\
\hline $12-10-1957$ & $\begin{array}{l}0 \\
0\end{array}$ & $\begin{array}{l}\text { - Cambia el Comité Ejecutivo Nacional. } \\
\text { - Nombra candidatos para la elección de } 1958 .\end{array}$ \\
\hline 30 y $31-08-1958$ & 0 & - Cambia el Comité Ejecutivo Nacional. \\
\hline $07-10-1961$ & 0 & - Designación de candidato para la elección de 1962. \\
\hline $16-11-1961$ & 0 & - Alteraciones en listas de candidatos. \\
\hline $14-07-1962$ & 0 & - Cambia el Comité Ejecutivo Nacional. \\
\hline $08-08-1964$ & 0 & $\begin{array}{l}\text { - Reelección del Comité Ejecutivo Nacional. } \\
\text { - Modificación del estatuto. }\end{array}$ \\
\hline $19-06-1966$ & $\begin{array}{l}0 \\
0 \\
0 \\
0\end{array}$ & $\begin{array}{l}\text { - Nombra el Comité Político Nacional. } \\
\text { - Reelección del Comité Ejecutivo Nacional. } \\
\text { - Crea una Secretaría Ejecutiva. } \\
\text { - Crea un Comité de reestructuración del partido dividido en } 5 \text { comisiones. }\end{array}$ \\
\hline $01-07-1967$ & $\begin{array}{l}0 \\
0\end{array}$ & $\begin{array}{l}\text { - Cambia el secretario general del Comité Ejecutivo Nacional. } \\
\text { - Reforma general del estatuto. }\end{array}$ \\
\hline 02-08-1969 & 0 & - Cambia el tesorero del Comité Ejecutivo Nacional. \\
\hline 26-04-1970 & $\begin{array}{l}0 \\
0\end{array}$ & $\begin{array}{l}\text { - Cambia el presidente y el tesorero del Comité Ejecutivo Nacional. } \\
\text { - Crea Comisión de revisión de estatutos y del reglamento de la Juventud Liberacionista. }\end{array}$ \\
\hline $06-10-1973$ & $\begin{array}{l}0 \\
0\end{array}$ & $\begin{array}{l}\text { - Reelección del Comité Ejecutivo. } \\
\text { - Reforma general del estatuto. } \\
\end{array}$ \\
\hline 08-06-1974 & 0 & - Cambio de presidente del Comité Ejecutivo Nacional. \\
\hline $20-03-1976$ & 0 & - Cambio de tesorero del Comité Ejecutivo Nacional. \\
\hline 24-09-1978 & 0 & - Prótroga de nombramiento al presidente y al secretario general hasta 31-03-79. \\
\hline 07-07-1979 & 0 & - Cambio del Comité Ejecutivo Nacional. \\
\hline 07-10-1979 & 0 & - Reforma general del estatuto. \\
\hline 19-02-1984 & 0 & - Cambio de secretario general del Comité Ejecutivo Nacional. \\
\hline $27-06-1987$ & 0 & $\begin{array}{l}\text { - Cambio de tesorero y reelección del presidente y del secretario general del Comité Ejecutivo } \\
\text { Nacional. }\end{array}$ \\
\hline $17-01-1988$ & 0 & - Cambio de secretario general del Comité Ejecutivo Nacional. \\
\hline
\end{tabular}

Fuente: Elaboración propia a partir de los archivos del Registro de Partidos del Registro Civil. 
SERGIO ALFARO SALAS

SISTEMA ELECTORAL Y CAMBIO ORGANIZATIVO EN LOS PARTIDOS POLÍTICOS:

EL CASO DE COSTA RICA (1950-1998)

Cuadro VI b. Los cambios estatutarios enel PLN, 1990-1998

\begin{tabular}{|c|c|c|}
\hline $\begin{array}{l}\text { Fecha del cambio } \\
\text { estatutario }\end{array}$ & Categoria & Implicaciones del cambio \\
\hline 10-08-1991 & $\begin{array}{l}0 \\
1\end{array}$ & $\begin{array}{l}\text { - Ratificación del cambio de presidente y tesorero del Comité Ejecutivo Nacional electos el 25-05.91. } \\
\text { - Ratificación de un nuevo estatuto (discutido desde julio del } 88 \text { hasta febrero del 91). }\end{array}$ \\
\hline 18.02-1992 & 0 & - Reelección del secretario general del Comité Ejecutivo Nacional. \\
\hline 22.08 .1992 & $\begin{array}{l}0 \\
2 \\
0 \\
2 \\
0 \\
0 \\
0 \\
0 \\
2 \\
\end{array}$ & $\begin{array}{l}\text { - Reformas y adecuación del estatuto al derecho electoral y a la Ley de Promoción e Igualdad Real de la Mujer, cambian los siguientes aspectos: } \\
\text { - Definición del partido (principios generales). } \\
\text { - Designa a la ley electoral como norma supletoria del estatuto orgánico. } \\
\text { - Se ajustan los órganos legales (columna vertebral), tanto en su organización como en sus funciones y facultades. } \\
\text { - Ajusta el estatuto en cuanto a la publicación de las finanzas del partido. } \\
\text { - Define los é(́rganos Nacionales». } \\
\text { - Redefine el sistema de Convención Nacional. } \\
\text { - Varía las normas del Tribunal de Elecciones Internas. } \\
\text { - Crea los aOrganos Consultivos». } \\
\text { - Regula lo relativo a la participación política de la mujer. }\end{array}$ \\
\hline 19.09-1992 & $\begin{array}{l}1 \\
1\end{array}$ & $\begin{array}{l}\text { - Reforma lo relativo a la participación femenina. } \\
\text {. Concede un } 10 \% \text { del presupuesto para la formación política femenina. }\end{array}$ \\
\hline $03 \cdot 10 \cdot 1992$ & 0 & - Mjuste de los Órganos Consultivos. \\
\hline 01.08 .1993 & 0 & - Designa candidatos a la clección de 1994. \\
\hline $12 \cdot 11 \cdot 1993$ & 0 & - Ratifica los candidatos a las vicepresidencias para la clección de 1994. \\
\hline $29.04 \cdot 1994$ & 0 & . Cambia el presidente del Comité Ejecutivo Nacional. \\
\hline $25 \cdot 06-1994$ & 0 & - Cambia el sistema de elección de candidatos a diputados (por primarias y no por asambleas). \\
\hline 08-07-1995 & $\begin{array}{l}0 \\
0\end{array}$ & $\begin{array}{l}\text { - Cambia presidente y tesorero del Comité Ejecutivo Nacional. } \\
\text { - Elección de tres miembros del Directorio Politico Nacional. } \\
\end{array}$ \\
\hline 11.11 .1995 & $\begin{array}{l}0 \\
0\end{array}$ & $\begin{array}{l}\text { Elección de miembros del Tribunal de Elecciones Internas. } \\
\text { Cambia el secretario general. }\end{array}$ \\
\hline $31-08-1996$ & 0 & $\begin{array}{l}\text { - Rcforma al sistema de elección de candidatos a diputados, regidores y sindicos municipales. } \\
\text { - Elección de miembros del Tribunal de Ética y Disciplina. }\end{array}$ \\
\hline $26-10-1996$ & $\begin{array}{l}0 \\
0\end{array}$ & $\begin{array}{l}\text { - Cambia la integración del Congreso Nacional. } \\
\text { - Informe sobre Congreso de la Internacional Socialista. } \\
\end{array}$ \\
\hline $07 \cdot 12 \cdot 1996$ & 2 & Se plantea la necesidad de ajustes en el estatuto por cambio en el derecho clectoral. \\
\hline 21-03.1997 & $\begin{array}{l}0 \\
0 \\
0\end{array}$ & $\begin{array}{l}\text { Fija fecha para la elección de candidatos a diputado para la elección de } 1998 . \\
\text { Reforma las funciones de la Asamblea Nacional (nombramientos honorarios). } \\
\text { Caimbia las reglas de integración del Directorio Politico y de la Asamblea Nacional. }\end{array}$ \\
\hline $21 \cdot 05 \cdot 1997$ & $\begin{array}{l}0 \\
2 \\
1 \\
0 \\
0 \\
0 \\
0 \\
0 \\
0 \\
0 \\
1 \\
0 \\
2 \\
2 \\
2\end{array}$ & 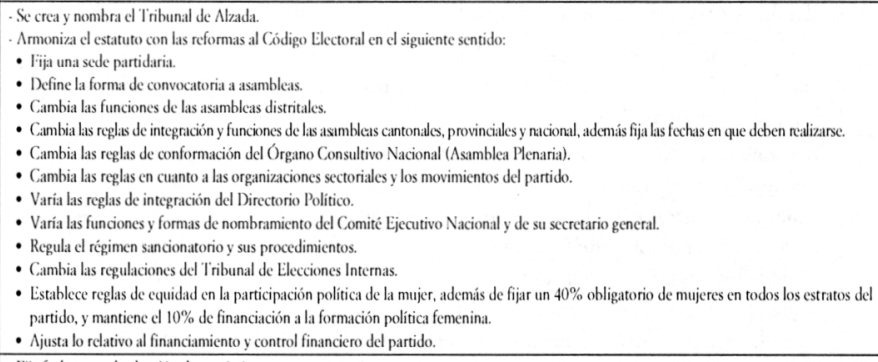 \\
\hline $15-07-1997$ & 0 & Fija fechas para la clección de movimientos y sectores. \\
\hline 23.07.1997 & $\begin{array}{l}0 \\
0 \\
0\end{array}$ & $\begin{array}{l}\text { - Modificación de estatutos: } \\
\text { - Cambia la composición de la Asamblea Plenaria. } \\
\text { - Ratifica al candidato presidencial para la clección de } 1998 . \\
\text { - Cambia fecha para la designación de candidatos a diputados. }\end{array}$ \\
\hline $22-08-1997$ & $\begin{array}{l}0 \\
0 \\
0 \\
0\end{array}$ & $\begin{array}{l}\text { - Trata el tema del cambio en el sistema de clección de los can didatos a diputados nacionales, regidores y síndicos municipales. } \\
\text { - Modificación al estatuto: } \\
\text { - Introducen cambios en el procedimiento sancionatorio. } \\
\text { - Cambia las reglas de conformación de las asambleas cantonales. } \\
\text { - Determina la forma de clección de candidatos en todos los niveles para la elección de } 1998 \text {. } \\
\text { - Elige a los candidatos a diputados para la elección de } 1998 .\end{array}$ \\
\hline $27 \cdot 09 \cdot 1997$ & 0 & $\begin{array}{l}\text { - Renuncian a la postulación dos candidatos a diputados por supuestos escíndalos de corrupción y problemas judiciales. } \\
\text { - Se retocan las listas para cumplir con el } 40 \% \text { de integración femenina de las listas de candidatos a diputados. }\end{array}$ \\
\hline 30-05-1998 & $\begin{array}{l}0 \\
0 \\
0\end{array}$ & $\begin{array}{l}\text { - Ajustes al estatuto en lo referente a las fechas de elccciones en movimientos y sectores. } \\
\text { - Nombramiento de integrantes del Tribunal de Ética y Disciplina. } \\
\text { - Reclección del secretario general. }\end{array}$ \\
\hline Seticmbre-1998 & 0 & - Cambio completo de la Carta Idcológica del partido a partir de un Congreso Nacional. \\
\hline
\end{tabular}

Fuente: Elaboración propia a partir de los archivos del Registro de Partidos del Registro Civil.

(ㄷ) Ediciones Universidad de Salamanca

América Latina Hoy, 27, 2001, pp. 67-87 
posible que no sea el cambio de legislación el que traiga un cambio en el partido, sino que sea el partido quien, en una actitud agresiva ante el medio, provoque el cambio legislativo con el fin de acaparar espacios de poder. El Cuadro vII muestra las leyes que, en principio, explican los cambios observados, así como un extracto de su contenido para facilitar la lectura del análisis.

\section{a. Los cambios en el PUAC}

Este partido, a pesar de su larga vigencia (nace en 1969), muestra poca actividad en lo que a cambios estatutarios se refiere. Se puede observar en toda su historia un único cambio, del total de siete cambios observados (14,3 por ciento), que se encuentra relacionado directamente con el cambio del derecho electoral. Éste es producto de la Asamblea Provincial del 18 de agosto de 1993 y consiste básicamente en dos puntos:

Cuadro VII. Las leyes más influyentes

\begin{tabular}{|c|c|}
\hline $\begin{array}{l}\text { LEY } 6833 \\
23-12-1982\end{array}$ & $\begin{array}{l}\text { - Regula la fusión de partidos políticos. } \\
\text { - Se cambia la regulación sobre funcionarios con prohibición de participación política. } \\
\text { - Reduce el porcentaje de votos necesarios para obtener financiamiento estatal de partidos políticos. }\end{array}$ \\
\hline & $\begin{array}{l}\text { - Aumenta los requisitos de inscripción de partidos políticos. } \\
\text { - Cambia los requisitos mínimos de contenido de los estatutos de partidos políticos. } \\
\text { - Regula la distribución del financiamiento estatal en las coaliciones de partidos. } \\
\text { - Cambia el sistema de adhesión para la inscripción de partidos. } \\
\text { - Cambia la regulación sobre designación de candidatos y limita temporalmente la realización de primarias. } \\
\text { - Regula la propaganda política y crea la «tregua navideña». } \\
\text { - Cambia las reglas del financiamiento estatal de partidos políticos. }\end{array}$ \\
\hline & $\begin{array}{l}\text { - Ley de Promoción e Igualdad Real de la Mujer. Establece que los partidos deben incorporar mecanismos eficaces } \\
\text { para mejorar la participación femenina en los partidos políticos y dedicar un porcentaje de su presupuesto para su } \\
\text { formación y participación. }\end{array}$ \\
\hline & $\begin{array}{l}\text { - Reforma las reglas de establecimiento de la división territorial administrativa. } \\
\text { - Aumenta los contenidos mínimos de los estatutos. } \\
\text { - Cambia la organización legal y jerarquiza las asambleas internas de los partidos, esencialmente impone medidas } \\
\text { de acción afirmativa a favor de la mujer. } \\
\text { - Cambia los requisitos para la coalición de partidos. } \\
\text { - Cambia las reglas de inscripción de partidos. } \\
\text { - Introduce, como causal de cancelación de la inscripción, la no participación en las elecciones. } \\
\text { - Cambia la regulación sobre la designación de candidatos. } \\
\text { - Regula la propaganda política, la realización de mítines, y la forma de reunión de los partidos. } \\
\text { - Cambia los criterios de prohibición de participación de funcionarios en actividades político electorales. } \\
\text { - Cambia el sistema de fiscales del partido ante el Registro Civil. } \\
\text { - Varía todo el sistema de financiamiento y control del financiamiento de los partidos. } \\
\text { - Permite la doble postulación de un candidato en tanto sea a presidente y diputado a la vez. } \\
\text { - Regula el transporte durante el día de las elecciones. } \\
\text { - Establece la obligación de inscripción y demostración de idoneidad a las empresas encuestadoras y prohíbe la } \\
\text { divulgación de encuestas desde dos días antes de la elección y el mismo día inclusive. }\end{array}$ \\
\hline $\begin{array}{c}\text { LEY } 7675 \\
02-07-1997\end{array}$ & $\begin{array}{l}\text { - Agrega, a modo de principio general, las condiciones y garantías de pluralismo, no discriminación por género, y } \\
\text { democracia interna de los partidos políticos. } \\
\text { - Varía las reglas del financiamiento estatal a los partidos, cambia al criterio del } 0,19 \% \text { del PIB del año trasanterior, el } \\
\text { umbral lo baja al } 4 \% \text { o la elección de un diputado para partidos provinciales. }\end{array}$ \\
\hline
\end{tabular}


el ajuste de los estatutos a los nuevos requerimientos mínimos obligatorios fijados por la ley y la inclusión del derecho a no ser discriminado por razones de género. El mismo incide en las tres dimensiones de afectación propuestas.

En cuanto a la primera dimensión, el perfeccionamiento institucional, la ley varía los requisitos mínimos de contenido en los estatutos, lo que obliga al partido a detallar aún más sus instrumentos legales. Esto supone una profesionalización forzosa de las actuaciones del partido dentro de las «reglas del juego» del sistema electoral. Además, la obligación de detallar las actividades partidistas en principio contribuiría a la sistematización de sus relaciones internas, lo cual, bajo la perspectiva de Panebianco (1982: 120), sería una contribución a la institucionalización del partido.

Lo dicho en el párrafo anterior también significa una afectación en la tercera dimensión, la del control estatal. Ésta se produce en términos de una imposición de las normas fijadas por el Estado sobre las reglas de juego interno que, en un sistema de absoluta libertad organizativa, pudieran generarse dentro de la organización. La fijación de este control, a través de un órgano fiscalizador, puede interpretarse como un intento de hacer respetar la normativa interna de la organización, lo que, a su vez, pretende garantizar una minimización de los efectos oligárquicos que se atribuyen a estas organizaciones políticas.

La segunda dimensión, referida al equilibrio interno de fuerzas, tiene que ver directamente con la estabilidad y cohesión de la coalición dominante (Panebianco, 1982: 315 323). La inclusión del derecho a la no discriminación por razones de género sería una alteración de ese equilibrio, ya que la ley pretende incorporar un nuevo grupo a la actividad interna y externa del partido. Para Panebianco esto significaría un debilitamiento de la institucionalización del partido ya que es una modificación del acuerdo que une a la coalición dominante.

Pese a que no hay evidencia suficiente para determinar los efectos reales de este cambio a nivel de la coalición dominante, es conveniente mencionar que el PUAC ha tenido un mismo presidente desde su creación, quien ha sido electo diputado en varias ocasiones y que, dada la imposibilidad de reelección sucesiva, se ha alternado en el cargo con familiares cercanos. Esto es indicador suficiente para catalogar a este partido como de tendencia monocrática (Panebianco, 1982: 323), lo que significa una fuerte cohesión en su coalición dominante. Dicha característica del PUAC dificultaría el debilitamiento de su institucionalización, aunque se produzca una variación en la composición de la coalición dominante.

\section{b. El Partido Fuerza Democrática}

En el caso de Fuerza Democrática podemos ver claramente dos afectaciones directas del derecho electoral sobre su estructura, en 1993 y en 1997, lo que significa el 22,2 por ciento de los cambios observados. Éstas se refieren a la participación femenina en la organización y ambas son producto de determinaciones legales que buscan dotar a la mujer de mayor actividad partidista. El primero de los cambios introduce en los 
estatutos los principios de igualdad de género y de no discriminación. El segundo ordena el establecimiento de cuotas de un 40 por ciento mínimo de participación femenina en las asambleas cantonales y provinciales lo que, dentro de los parámetros que hemos fijado, significaría una alteración de la composición de fuerzas internas del partido, segunda dimensión, elemento a tomar en cuenta en demérito de la institucionalización del mismo.

La reforma estatutaria de 1997 afecta la dimensión del perfeccionamiento organizativo, inducido por las nuevas regulaciones impuestas por las Leyes 7653 y 7675 , que modifican las reglas de financiación estatal de campañas políticas. Este partido, por haber obtenido en las dos elecciones en que ha participado más del 5 por ciento de los votos para la Asamblea Legislativa, tiene garantizado el aporte económico estatal. Esta realidad crea la necesidad de contar con una burocracia profesionalizada en su aparato financiero, lo que a su vez provoca una sistematización del partido en sus actividades políticas que favorece, siempre en la tónica indicada por Panebianco (1982: 315), la institucionalización de un partido muy joven, fundado apenas en 1993. La profesionalización que hemos señalado, que Panebianco reconoce como sistematización (1982: 120), coopera también con la institucionalización de la organización.

Es importante señalar la dimensión del control estatal, en este caso sobre el financiamiento y la composición de asambleas. La vigilancia estatal de los procesos internos requerirá a este partido un efectivo cumplimiento de sus estatutos y de la ley en estos dos ámbitos, lo que favorece la sistematización del funcionamiento interno de la organización y, a su vez, garantiza el cumplimiento de las exigencias legales y estatutarias sobre la participación femenina.

Fuerza Democrática ya ha cambiado una vez a su presidente y según Alfaro Salas (2001c), aún no se pueden vislumbrar líneas claras de liderazgo interno, el cual recae esencialmente en la cara legislativa del partido (actualmente tiene tres diputados). Esto indica que la cohesión de su coalición dominante puede ser aún débil y por ello la inclusión de nuevos actores podría traer inestabilidades en los acuerdos de las variadas y disímiles fuerzas internas que lo componen.

\section{c. El Partido Unidad Social Cristiana}

A pesar de que este partido es considerado como uno de los dos grandes del país, se observan pocos cambios relacionados con la variable en estudio. Así, de 36 cambios observados, en 3 tiene alguna influencia el derecho electoral y otros 3 pueden ser explicados directamente por él ( 8,33 por ciento).

Corresponde analizar estos últimos, dos de los cuales tienen lugar en las Asambleas Nacionales de junio de 1996 y de junio de 1997 y coinciden con los estudiados en el PUAC y en FD. Así, en dichos cambios, la dimensión de perfeccionamiento institucional, primera, se ve afectada por una mayor exigencia estatal de controles internos del partido respecto a los fondos públicos que recibe, lo que implica la profesionalización burocrática del partido, al menos en lo que a contabilidad se refiere. Este fenómeno de cambio en las normas de financiamiento público del partido también provoca un 
aumento del control estatal sobre la organización, tercera dimensión, lo que se traduce en procesos favorables a la sistematización de la organización, siempre dentro de las perspectivas que hemos analizado en los dos partidos anteriores.

La arista interesante que se vislumbra en el caso del pusc está en el cambio de estatutos observado en la Asamblea Nacional de octubre de 1991. En el mismo, además de una reforma general de la organización que nada tiene que ver con la reforma legal, se crea la Secretaría de Promoción y Participación Política de la Mujer. Al crear dicha secretaría el partido va más allá de las puras exigencias legales y saca ventaja frente a sus competidores. Esto es, en principio, una estrategia de promoción que implica tomar una posición agresiva ante el ambiente que lo rodea (Panebianco, 1982: 43), utilizando la profundización de la reforma más allá de lo estrictamente necesario, para con ello lograr una mayor resonancia de cara al público y la legitimación que eso significa.

Respecto de lo anterior, cabe mencionar que el PUSC es un partido controlado por un líder carismático y una coalición dominante cuyas pugnas de poder a lo interno de la organización no son fuertes, indicador de una coalición dominante altamente cohesionada (Alfaro Salas, 2001a). Esta característica de la organización le permite ir más allá de lo exigido por la ley en lo que a la incorporación de la mujer se refiere y con un riesgo mínimo de alteración de la composición y estabilidad de las fuerzas internas que integran la coalición dominante (segunda dimensión de afectación).

El tercero de los cambios observados y clasificados en la categoría 2, 21 de noviembre de 1983, parece influido directamente por el cambio de legislación (Ley 6833-82), pero según Pérez Brignoli (1998: 62), es un cambio que fue gestado por el propio partido, el cual negocia directamente la reforma del Código Electoral con el PLN que tenía en ese momento la presidencia de la República y mayoría absoluta en la Asamblea Legislativa. Esta situación implica una acción agresiva de la organización para controlar su entorno y provocar un cambio legislativo que les permitiera fusionar los partidos que hasta ahora eran parte de una coalición. En este caso el cambio organizativo es dependiente de otros factores aparte del cambio de legislación, el cual, a lo sumo, será un factor de tipo instrumental.

\section{d. El Partido Liberación Nacional}

Liberación Nacional es el partido más viejo de los analizados, fue fundado en 1952 y la cantidad de cambios que acumula durante su existencia supera con creces a los tres partidos anteriores, pero aun así podemos observar que de 89 cambios observados, solamente 13 tienen relación con el derecho electoral (14,61 por ciento) de los cuales 8 son calificados como directamente provocados por él (categoría 2), lo que significa un 9 por ciento.

El primero de éstos se produce en la década de 1950, época en la que se exigía a los partidos reinscribirse cada cuatro años, dicha norma provoca un «cambio con continuidad» en el cual la Asamblea Nacional del partido ratifica los mismos estatutos que lo regían, con fines de completar el acto jurídico de reinscripción, esto en el fondo no implica cambio alguno, mas sí un sometimiento al control estatal sobre los partidos 
políticos, que es la tercera dimensión propuesta y, por ende, una sistematización de sus actividades.

Los demás cambios de la categoría 2 comienzan a aparecer en agosto de 1992 y se acentúan en mayo de 1997. Éstos incluyen básicamente los temas de participación femenina y financiamiento estatal de las organizaciones partidistas que ya han sido tratados anteriormente.

Es interesante, en el caso del PLN, señalar que apenas un mes después de incluir los cambios mínimos sobre participación femenina que obliga la ley, el partido emprende una nueva reforma estatutaria que implica ajustes a lo dispuesto en agosto de 1992, dedicando con ello un 10 por ciento del presupuesto del partido a la formación política de este colectivo beneficiado por la reforma. Dicha disposición se mantendrá, inclusive, cuando se introduzcan las fórmulas de acción afirmativa femenina en las cuales la organización va más allá de lo mandado por la ley, extendiendo el porcentaje mínimo de participación (40 por ciento) no sólo a las asambleas cantonales y provinciales, sino también a la Asamblea Nacional y a las listas de candidatos que presenten en los diferentes niveles de elecciones.

El proceso descrito indica que, en este partido, la inclusión de un nuevo grupo provocó una verdadera alteración en la composición de fuerzas de la coalición dominante del partido -segunda dimensión- evidenciada por la profundidad del cambio. Las reformas estatutarias observadas hacen más fácil que una nueva fuerza se abra paso entre las fuerzas en pugna en el partido, lo que podría ser un signo de una institucionalización inacabada o bien de un proceso de recomposición de fuerzas en el acuerdo de la coalición dominante que controla el partido.

La tesis de la recomposición de fuerzas se ve reforzada por la muerte de uno de los fundadores del partido, su líder carismático tradicional José Figueres Ferrer, ocurrida en 1990. La desaparición del líder de referencia significó un vacío de poder y un aumento de las disputas internas en la coalición dominante (Alfaro Salas, 2001c), disputas que se ven agravadas por la inclusión del tema de la igualdad de género y el espacio abierto para la discusión interna por la Ley 7142.

En 1996, a raíz de una reforma profunda del Código Electoral, Ley 7563, y de otra reforma que se gestaba en la Asamblea Legislativa en ese momento, hoy Ley 7675 de 1997, el PLN inicia un largo proceso de reforma estatutaria el cual concluye en mayo de 1997. Este proceso incluyó cambios de las categorías 1 y 2, de acuerdo con el objetivo del presente estudio nos interesan los tres cambios explicados directamente por el cambio en el derecho electoral. El primero es la exigencia del nuevo código de fijar una sede partidista para recibir notificaciones del TSE, lo que no tiene mayor trascendencia; el segundo es la inclusión de cuotas femeninas, ya detallado; y el tercero tiene que ver con los cambios en el sistema de financiación.

Este último cambio supone una depuración y profesionalización del aparato burocrático del partido, necesaria para hacer efectivo el traslado de fondos públicos hacia la organización. Esto tiene que ver tanto con la primera dimensión de afectación como con la tercera, que también provoca una mayor sistematización del funcionamiento organizativo, situación que, como ya se ha dicho, contribuye a su institucionalización. 


\section{CONSIDERACIONES FINALES}

En el estudio de estas cuatro organizaciones partidistas costarricenses se observa que la sensibilidad al derecho electoral no es la causa mayor de los cambios en las estructuras formales, más bien todo lo contrario, el cambio de la legislación es una variable independiente residual frente a la multitud de movimientos que no pueden explicarse desde esta perspectiva, lo que provoca el rechazo de la hipótesis planteada.

El Cuadro VIII muestra un resumen de los datos que pueden obtenerse del estudio realizado, en él es notorio que los dos partidos «pequeños», PUAC y FD, parecen tener una mayor incidencia de la variable que los «grandes». Esto puede ser explicado desde la poca cantidad de cambios que aquéllos presentan, situación que, a su vez, provoca una desviación de la media de los porcentajes hacia arriba, inutilizando el dato. Por ello se opta por presentar también los datos acumulados, lo que arroja unas cifras más acordes con lo que sucede en la realidad.

Cuadro VIII. Cuadro resumen. Cambios explicados directamente por el derecho electoral

\begin{tabular}{|c|c|c|c|c|}
\hline \multirow{2}{*}{ Partido político } & \multirow{2}{*}{$\begin{array}{c}\text { Total de } \\
\text { cambios internos }\end{array}$} & \multirow{2}{*}{$\begin{array}{c}\text { Total de cambios } \\
\text { de categoría } 2\end{array}$} & \multicolumn{2}{|c|}{$\begin{array}{c}\text { Cambios en que el derecho electoral resulta } \\
\text { explicativo }\end{array}$} \\
\hline & & & Porcentaje & Media \\
\hline PUAC & 7 & 1 & 14,3 & \multirow{4}{*}{13,45} \\
\hline FD & 9 & 2 & 22,2 & \\
\hline PUSC & 36 & 3 & 8,3 & \\
\hline PLN & 89 & 8 & 9,0 & \\
\hline Total de cambios agregado & 141 & 14 & & \\
\hline
\end{tabular}

Fuente: Elaboración propia.

Según lo expuesto, la variación del derecho electoral sólo explica un 10\% de los cambios registrados pero, a pesar de la poca capacidad explicativa de esta variable, se puede destacar que los partidos costarricenses estudiados han sido afectados fuertemente por dos cambios legales, específicos e identificables, sucedidos en la década de 1990. Primero, la apertura hacia la participación femenina en las organizaciones y, segundo, la reorganización del financiamiento estatal de la política. También es posible observar que cada una de las organizaciones ha reaccionado de forma diferente ante tales cambios forzados, resolviendo a su manera los inconvenientes que los mismos han provocado en la estabilidad lograda en sus coaliciones dominantes y estructuras organizativas.

El presente análisis facilita, en futuras investigaciones, fijar la mirada en los dos cambios señalados como relevantes y que deben ser analizados con profundidad. Además, el objetivo esencial del trabajo se cumple al encontrar un método mediante el cual discriminar qué cambios deben observarse únicamente desde la perspectiva del derecho electoral, en cuáles debe ser tomada en cuenta esta perspectiva junto con otros factores y en qué situaciones es inútil ahondar buscando como causa dicha variable. Además se observa la utilidad de las dimensiones propuestas, las cuales pueden ser tomadas en cuenta para estudiar la incidencia de otras variables tanto sobre el funcionamiento 
formal de los partidos políticos como sobre el funcionamiento real. Futuros estudios de este tipo podrán fijar la verdadera capacidad de influencia de las reformas legales tendientes a la democratización de los partidos políticos y a su control por parte del Estado y de los órganos electorales.

Se dejan por atar muchos cabos, pero también se generan preguntas por resolver y cuestiones en que pensar. Ahora se sabe que resulta inútil buscar, en el caso costarricense, incidencias del derecho electoral más allá de los dos procesos descritos que afectan de forma común a los partidos observados.

\section{BIBLIOGRAFÍA}

Alfaro Salas, Sergio Iván. El Partido Liberación Nacional. En AlCÁntara, Manuel y FreidenBERG, Flavia (eds.). Los partidos políticos en América Latina. Salamanca: Ediciones Universidad de Salamanca, 2001a. En prensa.

- El Partido Unidad Social Cristiana. En AlCÁntara, Manuel y Freidenberg, Flavia (eds). Los partidos politicos en América Latina. Salamanca: Ediciones Universidad de Salamanca, 2001b. En prensa.

- El Partido Fuerza Democrática. En AlCÁntara, Manuel y Freidenberg, Flavia (eds.). Los partidos políticos en América Latina. Salamanca: Ediciones Universidad de Salamanca, 2001c. En prensa.

Crespo, Ismael. El Sistema Electoral. En AlCÁntara, Manuel y MarTíneZ, Antonia (eds.). Política y Gobierno en España. Valencia: Tirant lo Blanch, 1997.

HunTINGTON, Samuel P. El orden político en las sociedades en cambio. Barcelona: Ediciones Paidós, cuarta reimpresión, 1997. Primera edición en inglés 1968.

Katz, Richard y MAIR, Peter. Three Faces of Party Organization: Adaptation and Change. Working Paper. XII World Congress of Sociology. Madrid, 1990.

- (eds.). How Parties Organize. Londres: Sage Publications, 1994.

Michels, Robert. Los Partidos Políticos: Un estudio sociológico de las tendencias oligárquicas de la democracia moderna. Buenos Aires: Amorrortu Editores, quinta reimpresión, 1996. Primera edición en francés 1915.

Panebianco, Angelo. Modelos de Partido. Madrid: Alianza Editorial, 1990. Primera edición en italiano 1982.

Pérez Brignoli, Héctor. Historia del Partido Unidad Social Cristiana. ICEP-San José: Konrad Adenauer Stiftung, 1998.

Santaolalla López, Fernando. Partido Político, Grupo Parlamentario y Diputado. En GonZÁlez ENCINAR, Juan José (coord.). Derecho de Partidos. Madrid: Espasa-Universidad, 1992.

Vallès, Josep M. y Bosch, Agustí. Sistemas Electorales y Gobierno Representativo. Barcelona: Ariel, 1997. 
Achivos Oficiales:

Archivos del Registro de Partidos del Registro Civil: Relación histórica de estatutos partidarios de los partidos Liberación Nacional, Unidad Social Cristiana, Fuerza Democrática y Unión Agrícola Cartaginés.

Base de Datos del Sistema Nacional de Legislación Vigente (SINALEVI) de la Procuraduría General de la República: Constitución Política, texto original y todas sus reformas. Código Electoral, texto original y todas sus reformas.

Tribunal Supremo de Elecciones, http://www.tse.go.cr, sección de estadísticas electorales.

Leyes Publicadas:

Constitución Política de la República de Costa Rica, Editorial Investigaciones Jurídicas S.A., San José, julio 1998.

Código Electoral, Editorial Investigaciones Jurídicas S.A., San José, 1997.

Código Municipal, Editorial Investigaciones Jurídicas S.A., San José, 1998.

Ley de Igualdad Social de la Mujer, en http://www.pgr.go.cr/scij/. 